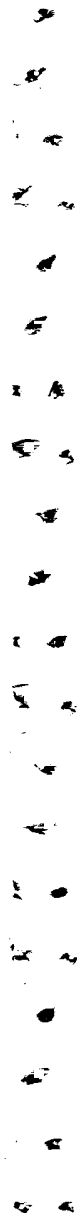

3
4
4
4
4
4

4

*

$-$

29

$\leftarrow$

$\infty$

$=5$

$+x$

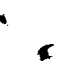

$\boldsymbol{s}$

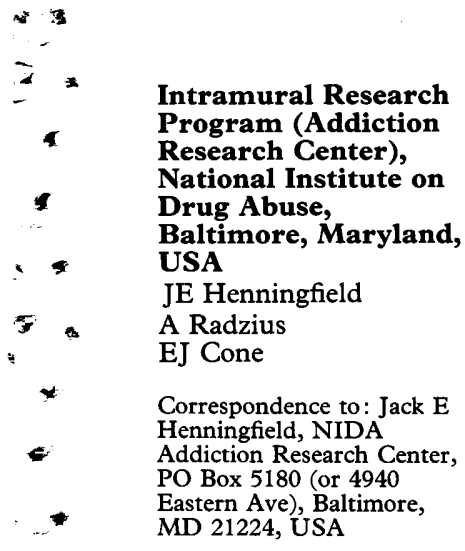

\title{
Estimation of available nicotine content of six smokeless tobacco products
}

\author{
Jack E Henningfield, Aleksandras Radzius, Edward J Cone
}

\begin{abstract}
Objective - To determine if nicotine content and pH vary among a series of smokeless tobacco products and if nicotine dosage would be altered selectively. Methods - The pH level and nicotine concentration were determined in six smokeless tobacco products. The tests were performed on four sets of samples bought in three regions of the US. Free, unionised nicotine, available for absorption, was estimated mathematically with the Henderson-Hasselbalch equation.

Results - Nicotine concentrations of the tobacco products were $7.5 \mathrm{mg}$ nicotine per gram of wet (undried) tobacco for Skoal Bandits Wintergreen and ranged from 10.3 to $11.4 \mathrm{mg} / \mathrm{g}$ for the other five products. The pH levels were 6.9 for Skoal Bandits Wintergreen, 8.6 for Copenhagen Snuff, and ranged from 7.4 to 7.6 for the other products. These data enabled the identification of four levels of available nicotine across products, with free nicotine estimates in aqueous solutions ranging from $7 \%$ to $79 \%$.

Conclusions - Nicotine dosing capability shows wide variation across products and is determined by the nicotine content and pH level. Manipulation of $\mathrm{pH}$ appears to be the primary means of nicotine dose control. Human bioavailability testing would be required to determine actual amounts and rates of nicotine absorbed per gram of the various products and to determine the influence of factors such as tobacco cut and other chemical additives.
\end{abstract}

(Tobacco Control 1995; 4: 57-61)

Keywords: smokeless tobacco; nicotine content

\section{Introduction}

An epidemic of smokeless tobacco use occurred among male adolescents in the US in the 1970s and 1980s. Among 17- to 19-year-old youths, $1.5 \%$ of men reported current use in 1970 ; by 1986 the percentage had increased to $10.6 \%{ }^{1,2}$ Recent surveys indicate that by 1992 , between $22 \%$ and $32 \%$ of high school seniors (mostly males) had reported using smokeless tobacco. ${ }^{2}$ These statistics are of grave concern because smokeless tobacco is a cause of oral cancers and other diseases. ${ }^{2,3}$ In addition, smokeless tobacco users are more likely to smoke cigarettes and abuse alcohol and illicit drugs than non-users of smokeless tobacco., ${ }^{1,2}$ This explosive growth of smokeless tobacco use among adolescents and young men was reportedly spawned and spread by the use of moist snufftype smokeless tobacco products designated "starter" products by the manufacturer., ${ }^{2,4}$ The use of starter products may have facilitated the initiation of use among young people. According to what was termed a "graduation strategy", marketing techniques ensured awareness of higher dosage products for those who developed a desire or need for higher doses (that is, products with more "satisfaction" or "taste"). ${ }^{2,4,5}$

The important characteristics of starter products appear to be use of low-nicotine dosage and incorporation of strong nontobacco flavours such as mint and cherry in the products. ${ }^{4}$ These factors may be more important with respect to smokeless tobacco than cigarettes. With cigarettes, virtually any brand is readily capable of providing the user with the desired dosage; thus, the nicotine intake from a cigarette is strongly determined by the smoking pattern of the user.$^{6,7}$ In contrast, the dose obtained from a unit ("dip" or "chew") of smokeless tobacco is primarily determined by the product itself and not the experience or actions of the user. ${ }^{8}$ The specific parameters by which nicotine dosage control of smokeless tobacco products are achieved, however, have not been quantified in the public scientific literature.

It has been generally assumed that the nicotine dosage of smokeless tobacco products is primarily controlled by (a) adjusting the concentration of nicotine in the tobacco product; (b) controlling the $\mathrm{pH}$ level of the product; and (c) adjusting the size of the tobacco cuttings. The manufacturer of one product type (Skoal Bandits) took dosage control one 0 step further by placing a half gram of tobacco in an enclosed pouch to control unit dosage. Other factors, such as chemicals that coat the tobacco cuttings or bind them together, may also influence the speed of nicotine release from the tobacco.

Unfortunately, there are few publicly available data on the actual dosing capabilities of $\delta$ smokeless tobacco products. A recent study reported the nicotine concentrations of several $\overline{\overline{0}}$ products but did not report the pH levels. ${ }^{9} \rightleftharpoons$ Without $\mathrm{pH}$ levels, nicotine content is of little value in comparing potential nicotine bioavailability across products. It is well known that vehicle $\mathrm{pH}$ is a crucial determinant of 
nicotine absorption through the nose and mouth. ${ }^{1}$ Thus, the mildly alkaline smoke of pipe and cigar tobacco in which the $\mathrm{pH}$ is frequently 7.5 or greater is well absorbed through the nose and mouth. In contrast, the smoke of flue-cured cigarette tobacco is mildly acidic, with values generally ranging from 5.5 to 6.0. Nicotine from cigarette smoke is poorly absorbed through the nasal and buccal mucosas. When smoke is inhaled into the lungs, however, $\mathrm{pH}$ is less important, and nicotine is rapidly absorbed and distributed throughout the body. ${ }^{1}$ An example of the importance of $\mathrm{pH}$ on absorption of nicotine in the mouth was the demonstration that nicotine absorption from nicotine polacrilex (gum) could be reduced to a minimum by intermittently consuming an acidic beverage such as a soft drink or coffee. ${ }^{10}$

The purpose of this study was to evaluate the $\mathrm{pH}$ level and nicotine concentrations of several smokeless tobacco products, and to estimate the amount of free nicotine available for immediate absorption.

\section{Methods}

PRODUCTS TESTED

Six smokeless tobacco product brands of the US Tobacco Company (Franklin Park, Illinois) were purchased from: Baltimore, Maryland; a suburb of Baltimore; Lansing, Michigan; and Boston, Massachusetts. The products were: Skoal Bandits Wintergreen; Skoal Long Cut Straight; Skoal Long Cut Wintergreen; Skoal Long Cut Cherry; Skoal Original Fine Cut; and Copenhagen Snuff. These products were chosen to reflect a crosssection of products from the company that supplies approximately $86 \%$ of the US moist snuff market, ${ }^{11}$ accounting for much of the explosive growth in sales of this category of tobacco product to young people. ${ }^{4,5}$ The smokeless tobacco samples were kept refrigerated in their original containers until testing. Only the Copenhagen Snuff containers were dated. These dates indicated that, at the time of testing, the product ages were: 38 days, Baltimore; 136 days, Baltimore suburb; 23 days, Lansing; 37 days, Boston.

\section{pH MEASUREMENTS}

Samples were tested within 24 hours of their receipt in the laboratory. Each product was tested individually by placing $2 \mathrm{~g}$ of tobacco and $10 \mathrm{ml}$ of de-ionised distilled water into a $50 \mathrm{ml}$ polypropylene container. These values were based on data from a study of smokeless tobacco which found that experienced users typically self-administered about $2 \mathrm{~g}$ per dose, ${ }^{12}$ and our own, unpublished data which indicated that people chewing gum were generally able to expectorate about $5-20 \mathrm{ml}$ of saliva. Preliminary $\mathrm{pH}$ testing in our laboratory revealed no difference in values obtained from $2 \mathrm{~g}$ tobacco mixed in 5,10 , or $20 \mathrm{ml}$ water. A Teflon-coated magnetic stirring bar was placed in the container and the mixture was stirred continuously throughout testing. Measurements of $\mathrm{pH}$ were made with an Orion Model SA $720 \mathrm{pH}$ meter equipped with an Orion 8103 Ross Combination pH electrode. The electrodes were calibrated with standard $\mathrm{pH} 7.00$ and 4.01 buffers. The mean of $\mathrm{pH}$ values determined at $5,15,30$, and 60 minutes is reported because there was no systematic variation in $\mathrm{pH}$ value over this time interval.

DETERMINATION OF NICOTINE CONCENTRATION Two-gram samples of each product were analysed by the Department of Psychiatry Neuroendocrine Laboratory, University of Michigan, Ann Arbor, Michigan, for nicotine content determined in milligrams per gram. Nicotine content was measured by high performance liquid chromatography, using $\mathrm{N}$ ethylnornicotine as the internal standard. The extraction of nicotine from the tobacco was performed by a modification of the method of Gottscho $e t a l^{13}$ The inter-assay coefficient of variance $(\mathrm{CV})$ of this method is $4 \%$ and the intra-assay $\mathrm{CV}$ is $3.6 \%$ in the concentration range $0.1-15 \mathrm{mg}$ nicotine. Additional details of the procedure have been described elsewhere. ${ }^{14}$

\section{ESTIMATION OF "FREE NICOTINE"}

\section{CONTENT}

Nicotine is released from the surface of the tobacco cutting into the mixed saliva of the mouth or to the buccal mucosa. This nicotine must then be transferred across the oral mucosa to be absorbed into the bloodstream. The speed of transfer and the amount of nicotine absorption are limited by a number of factors, including concentration, surface area, and pH. Only un-ionised ("uncharged" or "free") nicotine will be readily absorbed across the mucosa. Very high concentrations of nicotine base (un-ionised nicotine) will result in biologically significant levels being absorbed very quickly. If, however, the amount of unionised nicotine is low (that is, with most of the nicotine being ionised), the rate of absorption will be greatly diminished. This is because only the un-ionised form of nicotine, that is, free nicotine base, can cross biological membranes. Thus, ionised nicotine remains in the mouth until swallowed or until free nicotine is liberated by converting ionised nicotine to the un-ionised form.

The $\mathrm{pKa}$ of nicotine is $8.02 .{ }^{15}$ Consequently, at a pH of 8.02, half of the nicotine is in the un-ionised (non-charged) form and thereby immediately free for absorption, and the other portion is ionised. At acidic $\mathrm{pH}$ levels (below 7.0) more than $90 \%$ of the nicotine is ionised, leaving very little free nicotine to be absorbed at any point in time.

The impact of $\mathrm{pH}$ on the rate of absorption of chemicals across membranes can be modelled mathematically using the HendersonHasselbalch equation to estimate the proportion of total nicotine that is un-ionised. ${ }^{16}$ 
We used this equation to estimate the free nicotine content of each smokeless tobacco product as follows:

$\mathrm{pH}=\mathrm{pKa}+\log \frac{[\mathrm{B}]}{\left[\mathrm{BH}^{+}\right]}$

$\mathrm{B}+\mathrm{H}^{+} \rightleftharpoons \mathrm{BH}^{+}$

$\%$ free base nicotine $=\frac{\frac{[\mathrm{B}]}{\left[\mathrm{BH}^{+}\right]}}{\frac{[\mathrm{B}]}{\left[\mathrm{BH}^{+}\right]}+1} \times 100$

where $\mathrm{pKa}=8.02 ;[\mathrm{B}]=$ amount of absorbable free base nicotine and $\left[\mathrm{BH}^{+}\right]=$amount of unabsorbable ionised nicotine.

\section{Results}

NICOTINE AND pH LEVELS

The mean nicotine concentrations of the tobacco products were $7.5 \mathrm{mg} / \mathrm{g}$ for one product (Skoal Bandits Wintergreen), and ranged from 10.3 to $11.4 \mathrm{mg} / \mathrm{g}$ for the other products (table 1). The table shows that some variation was also observed within products.

The mean $\mathrm{pH}$ levels ranged from 6.9 for Skoal Bandits Wintergreen to 8.6 for Copenhagen Snuff (table 2). As shown, $\mathrm{pH}$ ranged from only 7.4 to 7.6 for the four other products. The within-brand variation in $\mathrm{pH}$ was greatest for Copenhagen in which it ranged from 7.93 to 9.07 .

FREE NICOTINE ESTIMATES

The figure shows that free nicotine levels for the six tobacco products ranged from 7 to $79 \%$. The figure also shows that the free

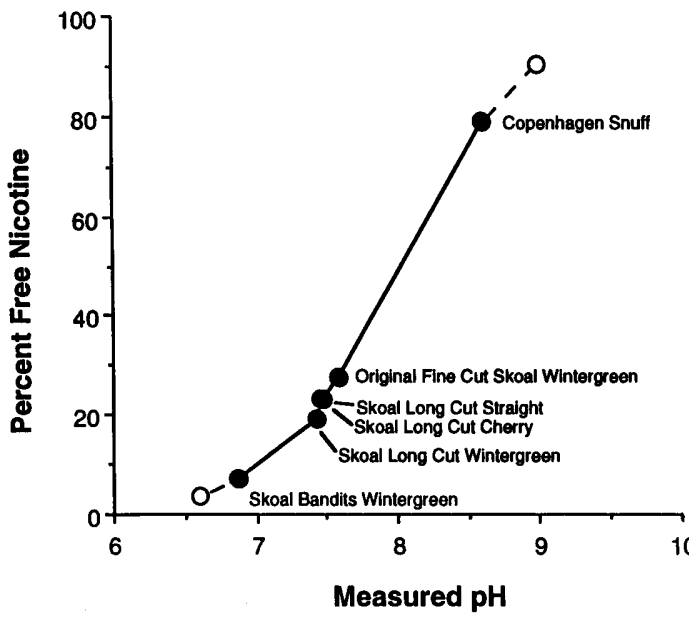

Calculated proportion of unprotonated or free nicotine based on the $p H$ measured for each product, calculated with the Henderson-Hasselbalch equation. Open circles are free nicotine levels at $p H$ values of 6.6 or 9.0.

nicotine levels would be $3 \%$ at a pH of 6.6 and $91 \%$ at a $\mathrm{pH}$ of 9.0 .

By multiplying percentage free nicotine by nicotine concentration, an estimate of total free nicotine available from these smokeless tobacco samples can be obtained (table 3). These calculations show that there is potentially a 17 -fold range of variation in nicotine dosing capability of these products. Specifically, as the table shows, the milligrams of free nicotine per gram of product ranges from a low of 0.53 for Skoal Bandits Wintergreen to 9.03 for Copenhagen Snuff. Note that Skoal

Table 1 Nicotine content $(\mathrm{mg} / \mathrm{g})$ of one $2 \mathrm{~g}$ sample of each smokeless tobacco product from each of the four geographical sites

\begin{tabular}{|c|c|c|c|c|c|}
\hline Product & $\begin{array}{c}\text { Baltimore } \\
\text { City }\end{array}$ & $\begin{array}{c}\text { Baltimore } \\
\text { suburb }\end{array}$ & Boston & Lansing & $\begin{array}{l}\text { Grand } \\
\text { mean }\end{array}$ \\
\hline $\begin{array}{l}\text { Skoal Bandits Wintergreen } \\
\text { Skoal Long Cut Straight } \\
\text { Skoal Long Cut Wintergreen } \\
\text { Skoal Long Cut Cherry } \\
\text { Original Fine Cut Skoal Wintergreen } \\
\text { Copenhagen Snuff }\end{array}$ & $\begin{array}{r}7.95 \\
8.10 \\
11.00 \\
12.86 \\
10.96 \\
13.37\end{array}$ & $\begin{array}{r}7.71 \\
10.96 \\
10.82 \\
11.37 \\
10.96 \\
9.74\end{array}$ & $\begin{array}{r}7.31 \\
10.89 \\
10.42 \\
10.01 \\
10.35 \\
10.42\end{array}$ & $\begin{array}{r}7.17 \\
11.23 \\
9.88 \\
11.50 \\
9.47 \\
11.91\end{array}$ & $\begin{array}{r}7.5 \\
10.3 \\
10.5 \\
11.4 \\
10.4 \\
11.4\end{array}$ \\
\hline
\end{tabular}

Table 2 Means of $\mathrm{pH}$ values measured when $2 \mathrm{~g}$ of a smokeless tobacco product were placed in $10 \mathrm{ml}$ of de-ionised water. The value for each product is the average of the values at $5,15,30$, and 60 minutes

\begin{tabular}{|c|c|c|c|c|c|}
\hline Product & $\begin{array}{c}\text { Baltimore } \\
\text { City }\end{array}$ & $\begin{array}{c}\text { Baltimore } \\
\text { suburb }\end{array}$ & Boston & Lansing & $\begin{array}{c}\text { Grand } \\
\text { mean }\end{array}$ \\
\hline $\begin{array}{l}\text { Skoal Bandits Wintergreen } \\
\text { Skoal Long Cut Straight } \\
\text { Skoal Long Cut Wintergreen } \\
\text { Skoal Long Cut Cherry } \\
\text { Original Fine Cut Skoal Wintergreen } \\
\text { Copenhagen Snuff }\end{array}$ & $\begin{array}{l}7.14 \\
7.33 \\
7.40 \\
7.60 \\
7.73 \\
9.07\end{array}$ & $\begin{array}{l}7.07 \\
7.81 \\
7.48 \\
7.31 \\
7.48 \\
8.75\end{array}$ & $\begin{array}{l}6.60 \\
7.47 \\
7.31 \\
7.51 \\
7.45 \\
8.65\end{array}$ & $\begin{array}{l}6.67 \\
7.25 \\
7.52 \\
7.42 \\
7.67 \\
7.93\end{array}$ & $\begin{array}{l}6.9 \\
7.5 \\
7.4 \\
7.5 \\
7.6 \\
8.6\end{array}$ \\
\hline
\end{tabular}

Table 3 Total free nicotine $(\mathrm{mg} / \mathrm{g})$ of each smokeless tobacco product from calculations based on the HendersonHasselbalch equation

\begin{tabular}{|c|c|c|c|c|}
\hline Product & $p H$ & $\begin{array}{l}\text { Un-ionised/ionised } \\
\text { nicotine ratio }\end{array}$ & $\begin{array}{c}\text { Free } \\
\text { nicotine }(\%)\end{array}$ & $\begin{array}{c}\text { Total free } \\
\text { nicotine } \\
(\mathrm{mg} / \mathrm{g})\end{array}$ \\
\hline Skoal Bandits Wintergreen & 6.9 & 0.038 & 7.05 & 0.53 \\
\hline Skoal Long Cut Straight & 7.5 & 0.302 & 23.19 & 2.39 \\
\hline Skoal Long Cut Wintergreen & 7.4 & 0.240 & 19.35 & 2.03 \\
\hline Skoal Long Cut Cherry & 7.5 & 0.302 & 23.19 & 2.64 \\
\hline Original Fine Cut Skoal Wintergreen & 7.6 & 0.380 & 27.55 & 2.87 \\
\hline Copenhagen Snuff & 8.6 & 3.802 & 79.17 & 9.03 \\
\hline
\end{tabular}


Bandits Wintergreen are actually provided in $0.5 \mathrm{~g}$ pouches and would thereby only provide $0.265 \mathrm{~g}$ of free nicotine per pouch.

\section{Discussion}

The results of this study indicate that a graduated series of $\mathrm{pH}$ levels exists across the six smokeless tobacco products tested. This results in alteration of the amount of nicotine available for absorption and ultimately determines the dose of nicotine delivered to the user. The range of variation could be as great as 17-fold when estimates of actual nicotine delivering capability across products are calculated. There was some regional variation among the $\mathrm{pH}$ and nicotine levels of the products, but the rank ordering of the products was generally similar. Interestingly, the Copenhagen Snuff samples with the highest $\mathrm{pH}$ also had aged the longest (38 and 136 days) since their stamped date of manufacture, suggesting the possibility that $\mathrm{pH}$ might increase after products leave the factory. Copenhagen Snuff was the only product tested that had distinctly dated packages.

The graduated changes in $\mathrm{pH}$ of the smokeless tobacco products are likely to primarily affect the rate of absorption of nicotine. Given sufficient time in the mouth, most of the nicotine released into saliva might eventually be absorbed through the mucosa. Thus, the main pharmacological impact of $\mathrm{pH}$ level is to determine the amount of nicotine that is immediately free when the tobacco product is placed in the mouth and hence the rate at which blood nicotine levels rise. This is an especially important consideration with respect to addictive drugs because studies with nicotine, ${ }^{17}$ cocaine, ${ }^{18}$ and pentobarbital ${ }^{19}$ suggest that the rate at which drugs are delivered is an important determinant of their psychoactive and reinforcing effects, with higher rates of delivery producing stronger effects. In nontolerant people, overly strong effects might produce sickness ("turning green") and lead to avoidance of drug use, whereas experienced and tolerant drug users often seek stronger effects.

Nicotine concentration of the tobacco is an important, and limiting, determinant of how much nicotine can be absorbed over any period of time. With the exception of Skoal Bandits
Wintergreen, however, which contained substantially less nicotine than other brands, the major factor determining the nicotine dosing characteristics of the products appears to be the $\mathrm{pH}$ level. Our data provide no information on the manufacturing processes used to control $\mathrm{pH}$ level. One report, however, has indicated that sodium carbonate and ammonium carbonate are added to increase the $\mathrm{pH}$ of the otherwise acidic tobaccos used to produce these smokeless tobacco products. ${ }^{4}$

The variation observed across these six products leads to our differentiation of four levels of nicotine dosing capability among these products. Table 4 shows these levels and the factors determining the levels. A factor that was considered in differentiating Original Fine Cut Wintergreen from the Long Cut products is the size and consistency of the tobacco cuttings. The Long Cut tobacco cuttings are approximately $0.4 \mathrm{~cm}$ in length and tend to stick together in clusters, apparently due to the adhesive quality of the flavourings and other additives. By contrast, Original Fine Cut Wintergreen had the appearance and consistency of a course powder, and would thus provide much greater tobacco surface area per gram of tobacco. These characteristics could result in the nicotine being released much more slowly from the Long Cut products than from Original Fine Cut Wintergreen.

When considering the estimated nicotine delivery values across products, it is important to note that several factors could influence the actual amount of nicotine absorbed. For example, the comparative calculations used in tables 1 and 3 are based on $1 \mathrm{~g}$ of tobacco, but Skoal Bandits Wintergreen are packaged in $0.5 \mathrm{~g}$ pouches and the other products are frequently used in quantities closer to $2 \mathrm{~g}^{12}$ Saliva might also alter nicotine absorption because the buffers it contains could alter the $\mathrm{pH}$ of the tobacco product. Thus, it would be plausible that, as a dip of snuff became saturated with saliva (which generally has a $\mathrm{pH}$ of $7.2-7.4^{10}$ ), the bioavailability of Skoal Bandits Wintergreen would increase somewhat, whereas that of the higher $\mathrm{pH}$ products would be reduced from that predicted by the Henderson-Hasselbalch model. Other factors that delay the release of nicotine from the tobacco itself, such as larger tobacco cuttings, chemical coatings, and the fibrous material used in the Skoal Bandits pouches, could also

Table 4 Categorisation of smokeless tobacco products based on the immediate nicotine dosing capabilities as influenced by the proposed nicotine delivery factors

\begin{tabular}{|c|c|c|c|}
\hline Dose & Free nicotine $(\%)$ & Product & Nicotine delivery factors \\
\hline Low & 7 & $\begin{array}{l}\text { Skoal Bandits } \\
\text { Wintergreen }\end{array}$ & $\begin{array}{l}\text { Low pH ( } 6.9) \\
\text { Low nicotine content }(7.5 \mathrm{mg} / \mathrm{g}) \\
\text { Coarse cut (in pouches) }\end{array}$ \\
\hline Medium & $19-23$ & $\begin{array}{l}\text { Skoal Long Cut } \\
\text { Straight } \\
\text { Wintergreen } \\
\text { Cherry }\end{array}$ & $\begin{array}{l}\text { About blood } \mathrm{pH}(7.4-7.5) \\
\text { Moderate nicotine content (10.3-11.4 mg/g) } \\
\text { Coarse cut ("sticky") }\end{array}$ \\
\hline Medium high & 28 & $\begin{array}{l}\text { Original Fine Cut } \\
\text { Skoal Wintergreen }\end{array}$ & $\begin{array}{l}\text { Higher pH ( } 7.6) \\
\text { Moderate nicotine content }(10.4 \mathrm{mg} / \mathrm{g}) \\
\text { Fine cut ("loose") }\end{array}$ \\
\hline Very high & 79 & Copenhagen Snuff & $\begin{array}{l}\text { Very high } \mathrm{pH}(8.6) \\
\text { Moderate nicotine content }(11.4 \mathrm{mg} / \mathrm{g}) \\
\text { Fine cut ("loose") }\end{array}$ \\
\hline
\end{tabular}


modulate nicotine absorption. Thus, although it is possible to rank-order products based on their predicted dosing characteristics, human bioavailability testing must be conducted to determine actual time course and amount of nicotine absorbed from each of these products.

In conclusion, although the present data cannot be used to predict actual serum nicotine levels achieved from each of the products tested, these data provide a clear basis for comparison of their available nicotine content (that is, free nicotine). With respect to potential product labelling implications of our data, it is important to note that the categories provided in table 4 only represent potential dosing capabilities of the various products upon their placement in the mouth. Human bioavailability testing would be required to determine the validity of these categories. The variation in nicotine dosing capabilities suggested by this study might be useful in the development of a system of smokeless tobacco product labelling based on nicotine dosing characteristics. If such an effort is undertaken, it would undoubtedly be useful also to consider labelling the products with respect to other chemicals of potential health significance, such as sodium and cancer-causing nitrosamines. This would be analogous to the proposal by Henningfield et $a l^{6}$ for developing meaningful nicotine dosing labels for cigarettes. Thus, it should be possible to provide meaningful nicotine dosing labels for smokeless tobacco products by basing free nicotine estimates on an analysis of tobacco nicotine content, tobacco $\mathrm{pH}$, the typical "serving size", and physical characteristics of the product with validation by human bioavailability testing.

1 US Department of Health and Human Services. The health consequences of smoking: nicotine addiction. A report of the Surgeon General, 1988. Rockville, Maryland: Centers for
Disease Control, Office on Smoking and Health, 1988. DHHS Publication No (CDC) 88-8406.)

2 US Department of Health and Human Services. Preventing tobacco use among young people. A report of the Surgeon General, 1994. Atlanta, Georgia: Public Health Service, Centers for Disease Control and Prevention, Office on Smoking and Health, 1994 (US Government Printing Office No S/N 017-001-00491-0)

3 Connolly GN, Winn DM, Hecht SS, Henningfield JE, Walker, Jr B, Hoffmann D. The reemergence of smokeless tobacco. N Engl f Med, 1986; 314:1020-7.

4 Freedman AM. How tobacco giant doctors snuff brands to boost their 'kick'. Wall Street $\mathcal{F} 199426$ Oct; A1.

5 Connolly GN, Orleans CT, Blum A. Snuffing tobacco out of sport. Am $\mathcal{F}$ Public Health 1992; 82: 351-3.

6 Henningfield JE. A proposal to develop meaningful labeling for cigarettes. $\mathcal{F} A M A$ 1994; 272 : $312-4$.

7 Slade J. Nicotine delivery devices. In: Orleans CT, Slade J, eds Nicotine addiction: principles and management. Oxford: Oxford University Press, 1993: 3-23.

8 Plaintiff's exhibit No, 3.27 "Pharmacokinetics of nicotine and its major metabolites in naive and habituated snuff takers," and No. 3.28 "Results of comparison of routes Cion [Snuff vs. Cigarette Smokng]". US District Court of the Western District of Oklahoma, Oklahoma City, No Civ -84-2777 R [1986].

9 Tilashalski K, Rodu B, Mayfield C. Assessing the nicotine content of smokeless tobacco products. $\mathcal{F} A D A 1994 ; 125$ : 590-5.

10 Henningfield JE, Radzius A, Cooper TM, Clayton RR. Drinking coffee and carbonated beverages blocks absorption of nicotine from nicotine polacrilex gum. $\mathcal{F} A M A$ $1990 ; 264: 1560-4$

11 Shapiro E. Upstart discounters invade snuff market. Wall Street f 19932 Aug: B1.

12 Hatsukami DK, Keenan RM, Anton DJ. Topographic features of smokeless tobacco use. Psychopharmacology 1988; 96: 428-9.

13 Gottscho AM, Lin JL, Duch WN, Losty TA. Nicotine analysis of commercial tobacco products. $\mathcal{F}$ Assoc Off Anal Chem 1988; 71: 1110

14 Hariharan M., VanNoord T., Greden J. F. A highperformance liquid-chromatographic method for routine simultaneous determination of nicotine and cotinine in plasma. Clin Chem 1988; 34: 724-9.

15 Lide DR, ed. CRC handbook of chemistry and physics. 72nd ed. 1991-2. Florida, Boca Raton: CRC Press, 1991.

16 Mudge GH, Weiner IM. Agents affecting volume and composition of body fluids. In: Gilman AG, Rall TW, Nies AS, Taylor P, eds. Goodman and Gilman's pharmacological basis of therapeutics. 8th ed. New York: pharmacological basis of therapeutics.

17 Henningfield JE, Keenan RM. Nicotine delivery kinetics and abuse liability. F Consult Clin Psychol 1993; 61: and abuse

18 Balster RL, Schuster CR. Fixed-interval schedule of cocaine reinforcement: effect of dose and infusion duration. $\mathcal{F}$ Exp Anal Behav 1973; 20 : 119-29.

19 de Wit H, Bodker B, Ambre J. Rate of increase of plasma drug level influences subjective response in humans. Psychopharmacology 1992; 107: 352-8. 